Sebastian R.

Schreglmann, MD

Ronald Bauer, MD

Stefan Hägele-Link, MD

Kailash P. Bhatia, MD

Parashkev Natchev, MD

Nikolas Wegener, MD

Anita Lebeda

Beat Werner, MSc

Ernst Martin, MD

Georg Kägi, MD

Correspondence to

Dr. Kägi:

georg.kaegi@kssg.ch
Supplemental data at Neurology.org

\section{Unilateral cerebellothalamic tract ablation in essential tremor by MRI-guided focused ultrasound}

\section{全}

\section{ABSTRACT}

Objective: To report results of a prospective trial of unilateral transcranial MRI-guided focused ultrasound (MRIgFUS) ablation of the cerebellothalamic tract in essential tremor (ET).

Methods: This was a prospective, uncontrolled, single-center interventional study. Patients with ET fulfilling criteria for interventional therapy received unilateral ablation of the cerebellothalamic tract (CTT) by MRIgFUS. Motor symptoms, manual dexterity, cognition, and quality of life were assessed before intervention and at 48 hours and 1, 3, and 6 months after intervention. Rating of standardized video recordings was blinded for evaluation time points. Primary outcome was the change in unilateral hand tremor score of the treated hand.

Results: Six patients received MRIgFUS ablation of the CTT contralateral to the treated hand. Repeated-measures comparison determined a statistically significant 83\% reduction (before vs 6 months after intervention mean \pm SD; absolute reduction; $95 \%$ confidence interval) in the unilateral treated hand subscore $(14.3 \pm 4.9$ vs $2.5 \pm 2.6 ; 11.8 ; 8.4-15.2 ; p<0.001)$, while quality of life improved by $52 \%(50.5 \pm 19.4$ vs $24.8 \pm 11.4 ; 25.7 ; 3.5-47.28 ; p=0.046)$. Measures for manual dexterity, attention and coordination, and overall cognition were unchanged. Transient side effects ( $n=3$ ) were ipsilateral hand clumsiness and mild gait instability for up to 3 months.

Conclusions: Unilateral MRIgFUS lesioning of the CTT was highly efficacious in reducing contralateral hand tremor in ET without affecting fine motor function and dexterity over 6 months of follow-up. Adverse effects were mild and transient.

Classification of evidence: This study provides Class IV evidence that for patients with ET, transcranial MRIgFUS ablation of the cerebellothalamic tract improves tremor. Neurology ${ }^{\circledast}$ 2017;88:1329-1333

\section{GLOSSARY}

$\mathbf{C T T}=$ cerebellothalamic tract; $\mathbf{D B S}=$ deep brain stimulation; $\mathbf{E T}=$ essential tremor; MRIgFUS $=$ MRI-guided focused ultrasound; PSA = posterior subthalamic area; VIM = ventral intermediate.

The thalamic ventral intermediate (Vim) nucleus is part of the network involved in essential tremor (ET) and the main stereotactic target for its treatment. It receives signals from the cerebellar output nuclei via the cerebellothalamic tract (CTT). ${ }^{1}$ Both the high anatomic density of CTT fibers before diverging within the Vim and its larger distance to sensory thalamic nuclei are conceptual advantages of the CTT as a stereotactic target, ${ }^{1}$ acknowledged by neurosurgeons performing subthalamotomies in the past. ${ }^{2}$ Deep brain stimulation (DBS) studies indicate that the best stimulation effect on tremor is achieved in the white matter tracts caudal to the Vim rather than the Vim itself. ${ }^{2,3}$ Recently, transcranial MRI-guided high-intensity focused ultrasound (MRIgFUS) has been established to induce thermal coagulation lesions through intact skull and brain tissue under direct MRI guidance. ${ }^{4}$ We have adopted the long-standing idea of subthalamotomy, i.e., CTT fiber tract ablation, for MRIgFUS treatment and report results from a prospective study of unilateral transcranial CTT MRIgFUS ablation in ET.

\footnotetext{
From the Departments of Neurology (S.R.S., S.H.-L., N.W., A.L., G.K.) and Neurosurgery (R.B.), Kantonsspital St. Gallen, Switzerland; Sobell Department of Motor Neuroscience and Movement Disorders (S.R.S., K.P.B.), University College London, Institute of Neurology, UK; Institute of Neurology (P.N.), Queen Square, London, UK; and Center for Focused Ultrasound (B.W., E.M.), University of Zurich, Children's Hospital Zurich, Switzerland.

Go to Neurology.org for full disclosures. Funding information and disclosures deemed relevant by the authors, if any, are provided at the end of the article.
} 


\begin{tabular}{|c|c|c|c|c|c|c|c|c|c|c|}
\hline Table & Democ & raphic and & clinical patier & characteristi & s, including t & reatment details & & & & \\
\hline No. & $\begin{array}{l}\text { Treated } \\
\text { hand }\end{array}$ & Age, y & $\begin{array}{l}\text { Disease } \\
\text { duration, y }\end{array}$ & $\begin{array}{l}\text { Medication at } \\
\text { MRIgFUS }\end{array}$ & $\begin{array}{l}\text { Target } \\
\text { coordinates }^{a}\end{array}$ & $\begin{array}{l}\text { Maximum } \\
\text { applied energy, J }\end{array}$ & $\begin{array}{l}\text { Sonications } \\
\text { administered, } \mathrm{n}^{\mathrm{b}}\end{array}$ & $\begin{array}{l}\text { Temperature } \\
\text { at first effect } \\
\text { on tremor, }{ }^{\circ} \mathrm{C}\end{array}$ & $\begin{array}{l}\text { Peak } \\
\text { temperature, } \\
{ }^{\circ} \mathrm{C}\end{array}$ & $\begin{array}{l}\text { Duration, } \\
\min ^{c}\end{array}$ \\
\hline 1 & $\mathrm{R}$ & 64 & 4 & None & $10 / 6.2 / 1$ & 19,950 & 17 & 52 & 58 & 305 \\
\hline 2 & $\mathrm{R}$ & 72 & 10 & Propranolol & $9 / 6 / 1$ & 11,500 & 10 & 48 & 60 & 300 \\
\hline 3 & $\mathrm{~L}$ & 75 & 56 & None & $10 / 7.7 / 1.8$ & 9,350 & 8 & 53 & 62 & 225 \\
\hline 4 & $\mathrm{R}$ & 58 & 43 & None & $9.7 / 7.2 / 2$ & 14,000 & 9 & 52 & 64 & 290 \\
\hline 5 & $\mathrm{R}$ & 82 & 32 & None & $10.8 / 6.5 / 2.8$ & 7,800 & 10 & 54 & 64 & 290 \\
\hline 6 & $\mathrm{R}$ & 73 & 2 & None & $10.5 / 6.7 / 0$ & 9,450 & 12 & 55 & 64 & 215 \\
\hline Mean & & $70.7 \pm 8.5$ & $24.5 \pm 22.5$ & & $10 / 6.7 / 1.4$ & $12,008 \pm 4,441$ & $11 \pm 3.2$ & $52.4 \pm 2.7$ & $62.0 \pm 2.5$ & $271 \pm 40$ \\
\hline
\end{tabular}

Abbreviation: MRIgFUS = MRI-guided focused ultrasound.

${ }^{a}$ Lateral/anterior-posterior/inferior of anterior commissure-posterior commissure plane (in millimeters).

${ }^{b}$ Lesion consolidation was attained by repeating the sonication that reached the peak temperature once more at unchanged settings

c Time from local anesthesia to frame removal.

METHODS Standard protocol approvals, registrations, and patient consent. This study was designed as a prospective, uncontrolled, single-center interventional study, approved by the ethics committee of St. Gallen, and conducted in accordance with national and international law and good clinical practice. All participants provided written informed consent for participation.

The primary research question was to determine the efficacy and safety of unilateral MRIgFUS ablation of the CTT in ET. Patients with a diagnosis of ET according to established criteria and insufficient symptom control were included. Incision-less CTT ablation was achieved with the ExAblate Neuro system. The target structure within the posterior subthalamic area (PSA) was

\section{Figure 1 Lesion placement, size, and development over time}

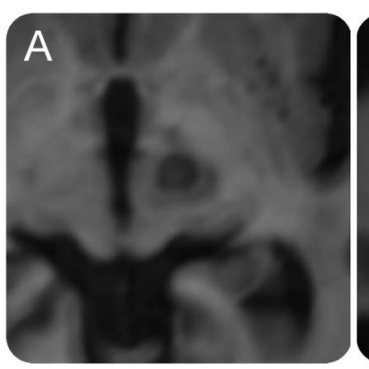

\section{B}
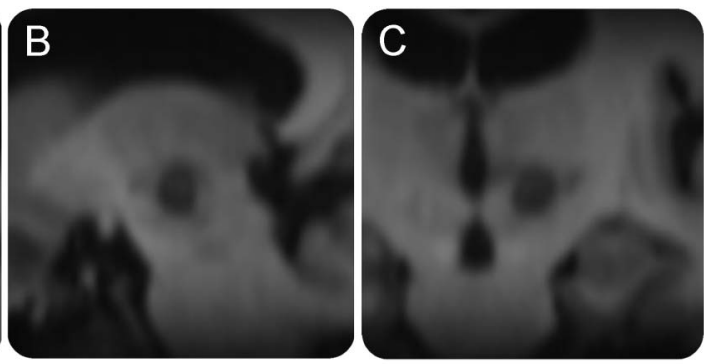

$\mathrm{D}$

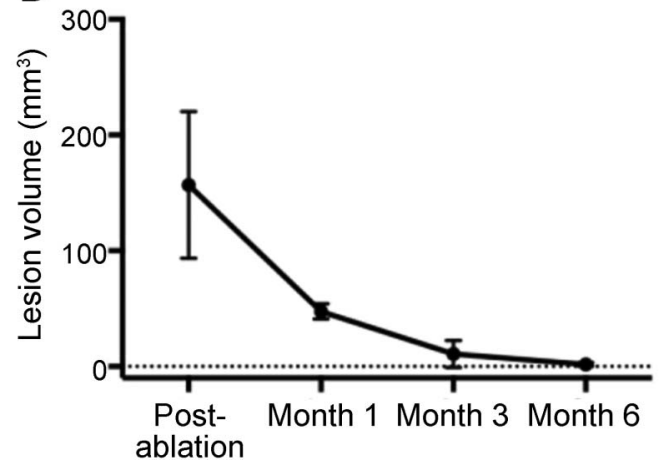

T1-weighted images showing the location and extent of the lesion in the posterior subthalamic area 2 days after MRI-guided focused ultrasound ablation in the axial (A), sagittal (B), and coronal (C) planes. Volume changes during 6-month follow-up document the rapid decrease in lesion volume, which is barely measurable from 3 months onward in most cases (D). identified on 3T MRIs by a combination of direct targeting and atlas-based ${ }^{5}$ coordinates. Interventions were performed as described previously. ${ }^{4}$

At study visits before and 48 hours and 1, 3, and 6 months after intervention, full neurologic examination, Clinical Rating Scale for Tremors, Quality of Life in Essential Tremor, and manual dexterity (9-hole peg test) were documented. Trail-Making Test $\mathrm{A}$ and $\mathrm{B}$ were used as a combined measure for working memory, interference control, and visuomotor speed, and the MiniMental State Examination and Montreal Cognitive Assessment were used for cognitive screening.

Standardized tremor video recordings from all visits were rated in random order and blinded for evaluation time point by a movement disorder neurologist not involved in the treatments (S.R.S.). Participants 4 and 5 were unavailable for evaluations at months 1 and 3 but attended all other time points. The primary endpoint was change in hand tremor severity. Repeated-measures comparisons using mixed linear model statistics and least significant difference post hoc test, as well as the Wilcoxon signed-rank test, were calculated with SPSS version 22 (IBM, Armonk, NY) (see supplemental data and figure e-1 at Neurology.org).

RESULTS The table summarizes interventional details of the participants who received unilateral MRIgFUS ablation of the CTT contralateral to the mainly affected, treated hand. Postinterventional MRI confirmed exact lesion placement within the PSA (figure 1, $\mathrm{A}-\mathrm{C}$ ), and there was no sign of bleeding on susceptibility-weighted MRI. The initial mean lesion size on T1-weighted images $\left(156.9 \pm 63.5 \mathrm{~mm}^{3}\right)$ decreased rapidly over time (figure 1D).

Clinically, the intervention had an immediate effect once a temperature $>55^{\circ} \mathrm{C}$ was reached (table). There was a statistically significant, persisting reduction in Clinical Rating Scale for Tremors score over the 6-month follow-up (repeated-measures statistics; mean $\pm S D$ at baseline vs 6 months after intervention; absolute reduction; 95\% confidence intervals; repeated measures statistics): overall sum (43.8 \pm 9.8 vs $19.8 \pm 6.8 ;-24.0 ;-18.1$ to $-29.9 ; p<$ 0.001 ) and unilateral hand score on the treated side 
$(14.3 \pm 4.9$ vs $2.5 \pm 2.6 ;-11.8 ;-8.4$ to -15.2 ; $p<0.001$ ) (figure 2 ; see supplemental data for additional information).
Wilcoxon signed-rank (2-tailed) test showed a significant $52 \%$ improvement in quality of life over the same period (Quality of Life in Essential Tremor

Figure 2 Clinical effect of unilateral MRIgFUS ablation of the CTT

A

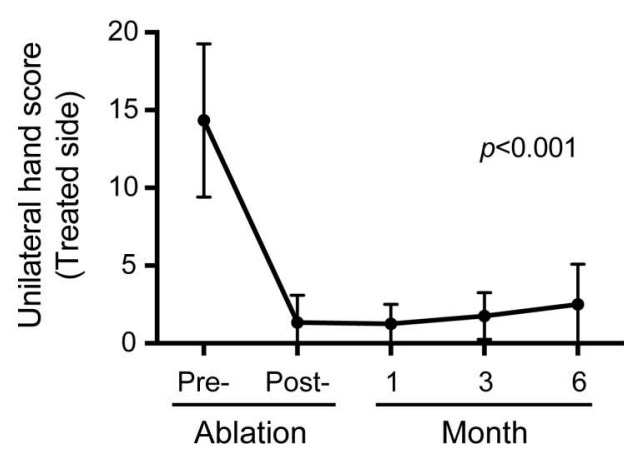

C

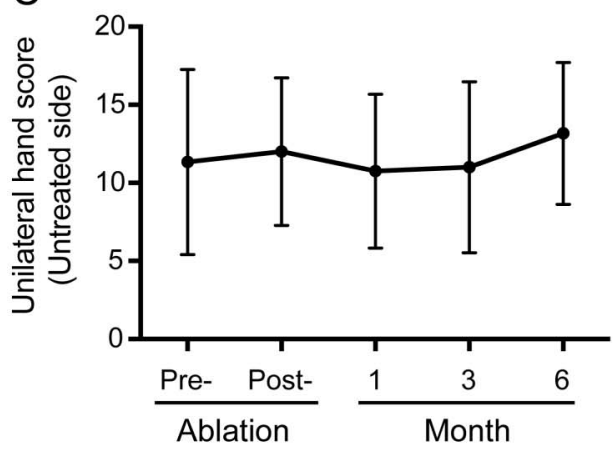

$\mathrm{E}$

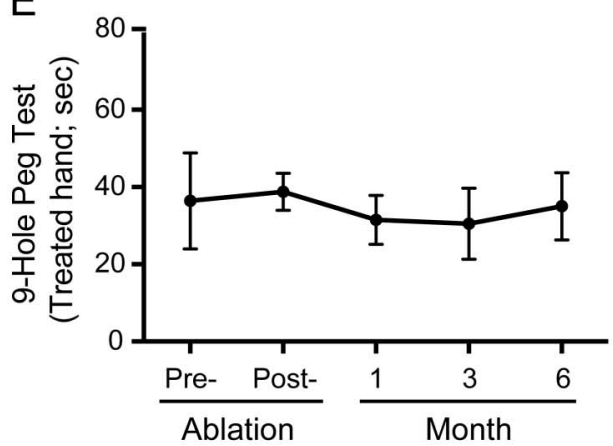

G

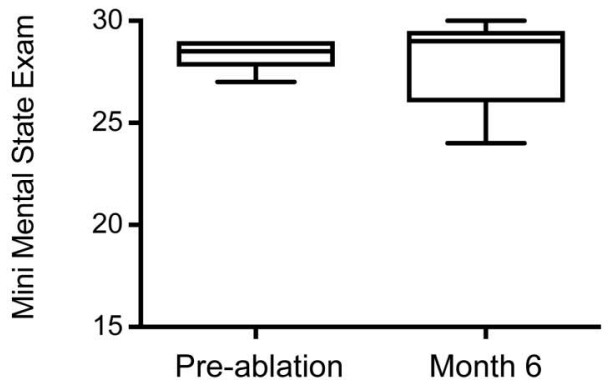

B
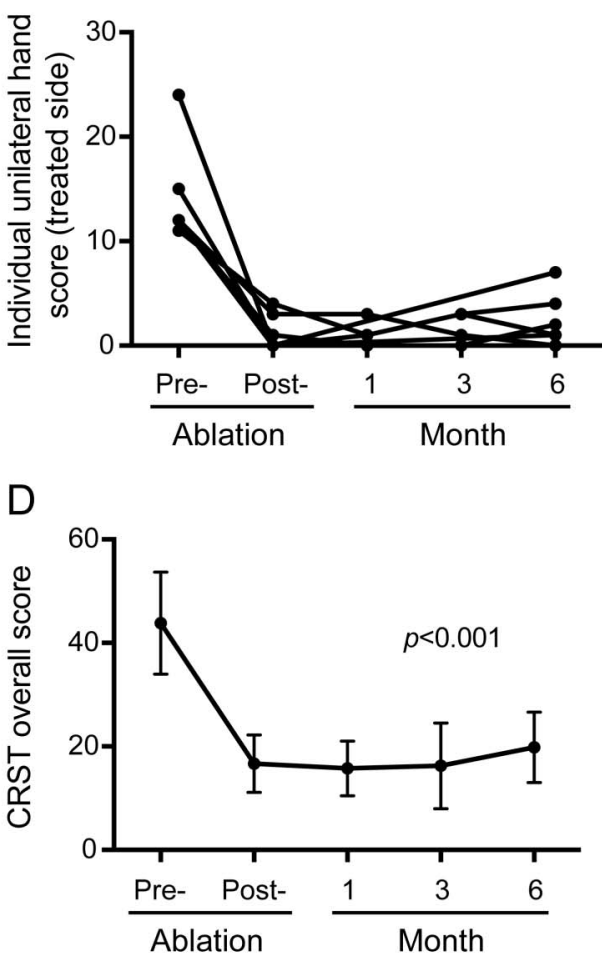

$\mathrm{F}$

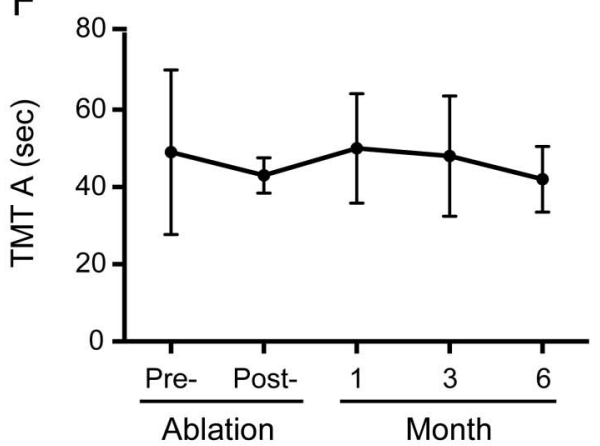

$\mathrm{H}$

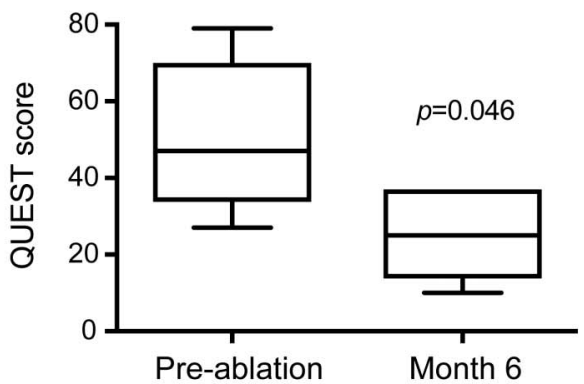

Six-month follow-up results of unilateral cerebellothalamic tract (CTT) MRI-guided focused ultrasound (MRIgFUS) lesion on Clinical Rating Scale for Tremors (CRST) scores of the treated (A, B) and untreated (C) hand and overall tremor severity (D), manual dexterity $(E)$, fine motor tasks $(F)$, cognition $(G)$, and quality of life $(H)$ in patients with advanced essential tremor. QUEST $=$ Quality of Life in Essential Tremor; TMT A = Trail-Making Test A. 
$p=0.046)$, whereas there were no significant changes in manual dexterity (9-hole peg test) in the treated and nontreated hand, concentration and fine motor (Trail-Making Test A and B), and cognitive screening (Mini-Mental State Examination, Montreal Cognitive Assessment).

During the procedure, vestibular symptoms were noted as immanently reversible side effects in 4 of 6 patients. They exclusively occurred during the final sonications that delivered the highest acoustic power per patient. After the procedure, subjective transient clumsiness of the treated hand $(\mathrm{n}=1)$ and gait instability $(n=1)$ and objective tendency to veer to the treated side $(\mathrm{n}=1)$ resolved within 3 months. No dyskinesia emerged.

Patient 5 had an unwitnessed fall at home 4 weeks after the intervention with an occipital fracture, intracranial hematoma, and retrograde amnesia for the event, necessitating hospitalization with eventual full recovery. Retrospect analysis revealed an unexplained fall 6 months before the intervention in this patient.

DISCUSSION This study is proof of principle that the exact and safe MRIgFUS ablation of white matter tracts within the PSA is potentially highly effective in ET.

Similar to MRIgFUS ET studies that targeted the $\mathrm{Vim},{ }^{6-8}$ there is immediate symptom suppression once a thermal threshold is reached. Our data suggest that thermal susceptibility and lesion volumetric changes are similar between white matter tissue and previously studied nuclear structures. ${ }^{6,7}$ We did not observe imaging changes along white matter tracts outside the sonication target, indicating a confined local effect. In humans, the CTT has been localized histologically ${ }^{1}$ and through advanced diffusion tensor imaging in vivo ${ }^{3}$ within the PSA. ${ }^{2}$ By using a targeting approach that combined atlas coordinates ${ }^{5}$ and individual anatomic landmarks, we accommodated for the known anatomic variability in the PSA, explaining minor deviations from mean literature PSA coordinates. ${ }^{2}$ Although these coordinates document that we aimed at the PSA, only postmortem analysis would allow ultimate target verification, as is true for all surgical targets that cannot be readily identified on MRI.

Clinical data presented here suggest highly efficacious symptomatic relief of unilateral hand tremor by contralateral CTT MRIgFUS ablation, as suggested by retrospective data. ${ }^{9}$ The $83 \%$ efficacy in this study is comparable to MRIgFUS Vim lesions in open-label $\operatorname{trials}^{6}(75 \%$ after 12 months; $\mathrm{n}=15)$, whereas a large double-blind MRIgFUS Vim study ${ }^{8}$ reported a lower efficacy rate ( $47 \%$ after 3 months, $n=76$ ). In contrast to studies aiming at the Vim nucleus, ${ }^{6,8}$ we observed no transient or persistent paresthesia after CTT ablation, possibly related to the larger anatomic distance of the
PSA to thalamic sensory structures. We provide evidence that CTT MRIgFUS ablation does not worsen manual dexterity and cognition, adding important information to the safety profile of this intervention.

Converging evidence points to a central origin for the fully reversible, intraprocedural vestibular symptoms observed by us and others ${ }^{6}$ : Vim DBS for ET can affect vestibulothalamic pathways. ${ }^{10}$ The steep gradient of acoustic energy of MRIgFUS also limits relevant effects to structures in the focus vicinity. The transient, mostly subclinical ipsilateral cerebellar side effects observed in part of our cohort are most likely a direct effect on the CTT or adjacent fiber tracts, as previously shown in PSA DBS. ${ }^{3}$ These observations warrant cerebellar and vestibular monitoring in future trials.

After careful evaluation, we do not think that the fall in participant 5 is causally related to the study procedure. The timing of the event and video-documented gait and postural control examination before and after intervention do not indicate any balance changes due to the intervention. Nevertheless, preintervention gait instability requires careful risk-benefit evaluation before PSA MRIgFUS ablation.

Larger trials with a longer follow-up are needed to adequately assess the long-term safety and efficacy of MRIgFUS CTT ablation. Meanwhile, our study backs the growing evidence for the efficacy of MRIgFUS ablation in ET and adds the CTT (Class IV evidence) as a suitable target.

\section{AUTHOR CONTRIBUTIONS}

S.R.S. was involved in conception and organization of the trial, executed the statistical analysis, and wrote the first manuscript draft. R.B., S.H.-L., N.W., and A.L. executed the study and critically reviewed the manuscript. K.P.B. was involved data analysis and critically reviewed the manuscript. P.N. was involved in data analysis and reviewed the manuscript. B.W. and E.M. were involved in the conception and execution of the study and critically reviewed the manuscript. G.K. was involved in conception, organization, and execution of the trial and critically reviewed the first draft and the manuscript.

\section{STUDY FUNDING}

No targeted funding reported.

\section{DISCLOSURE}

S. Schreglmann receives research grants from the Swiss National Science Foundation, Swiss Neurological Society, and European Academy of Neurology. He has received a research grant from the EMDO Foundation, Zurich, Switzerland. He reports no other financial disclosures. R. Bauer and S. Hägele-Link report no disclosures relevant to the manuscript. K. Bhatia received funding for travel from GlaxoSmithKline, Orion Corp, Ipsen, and Merz Pharmaceuticals, LLC; serves on the editorial board of Movement Disorders and Therapeutic Advances in Neurological Disorders; receives royalties from the publication of Oxford Specialist Handbook of Parkinson's Disease and Other Movement Disorders (Oxford University Press, 2008); received speaker honoraria from GlaxoSmithKline, Ipsen, Merz Pharmaceuticals, LLC, and Sun Pharmaceutical Industries Ltd; received personal compensation for scientific advisory board for GSK and Boehringer Ingelheim; received research support from Ipsen and the Halley Stewart Trust through Dystonia Society UK and the Wellcome Trust MRC strategic neurodegenerative disease initiative 
award (reference WT089698), a grant from the Dystonia Coalition, and a grant from Parkinson's UK (reference number G-1009); and is coapplicant on Parkinson disease UK grant K-1303, "Single-Centre Open Label Exploratory Phase 2 Pilot Study of Exogenous Oral Melatonin for the Treatment of Nocturia in Parkinson's disease." P. Natchev is funded by the Wellcome Trust and the National Institute for Health Research University College London Hospitals Biomedical Research Centre. N. Wegener, A. Lebeda, B. Werner, and E. Martin report no disclosures relevant to the manuscript. G. Kägi receives research grants from the Swiss Parkinson's disease Association, the Swiss Heart Foundation, and the Swiss National Science Foundation and is member of scientific advisory boards for Zambon, Bayer, Boehringer-Ingelheim, and Nestle. Go to Neurology.org for full disclosures.

Received September 22, 2016. Accepted in final form January 10, 2017.

\section{REFERENCES}

1. Gallay MN, Jeanmonod D, Liu J, Morel A. Human pallidothalamic and cerebellothalamic tracts: anatomical basis for functional stereotactic neurosurgery. Brain Struct Funct 2008;212:443-463.

2. Blomstedt P, Sandvik U, Fytagoridis A, Tisch S. The posterior subthalamic area in the treatment of movement disorders: past, present, and future. Neurosurgery 2009; 64:1029-1038; discussion 1038-1042.

3. Groppa S, Herzog J, Falk D, Riedel C, Deuschl G, Volkmann J. Physiological and anatomical decomposition of subthalamic neurostimulation effects in essential tremor. Brain 2014;137:109-121.

4. Martin E, Jeanmonod D, Morel A, Zadicario E, Werner B. High-intensity focused ultrasound for noninvasive functional neurosurgery. Ann Neurol 2009;66:858-861.

5. Morel A. Stereotactic Atlas of the Human Thalamus and Basal Ganglia. 1st ed. New York: Informa Healthcare; 2007.

6. Elias JW, Huss D, Voss T, et al. A pilot study of focused ultrasound thalamotomy for essential tremor. N Engl J Med 2013;369:640-648.

7. Chang WS, Jung HH, Kweon EJ, Zadicario E, Rachmilevitch I, Chang JW. Unilateral magnetic resonance guided focused ultrasound thalamotomy for essential tremor: practices and clinicoradiological outcomes. J Neurol Neurosurg Psychiatry 2015;86:257-264.

8. Elias WJ, Lipsman N, Ondo WG, et al. A randomized trial of focused ultrasound thalamotomy for essential tremor. N Engl J Med 2016;375:730-739.

9. Gallay MN, Moser D, Rossi F, et al. Incisionless transcranial MR-guided focused ultrasound in essential tremor: cerebellothalamic tractotomy. J Ther Ultrasound 2016;4:5.

10. Ceballos-Baumann AO, Boecker H, Fogel W, et al. Thalamic stimulation for essential tremor activates motor and deactivates vestibular cortex. Neurology 2001;56: 1347-1354.

\section{Subspecialty Alerts by E-mail!}

Customize your online journal experience by signing up for e-mail alerts related to your subspecialty or area of interest. Access this free service by visiting Neurology.org/site/subscriptions/etoc.xhtml or click on the "E-mail Alerts" link on the home page. An extensive list of subspecialties, methods, and study design choices will be available for you to choose from—allowing you priority alerts to cutting-edge research in your field!

\section{Get 10 AAN Practice Management Webinars for Less than \$19 Each}

The AAN is dedicated to helping neurologists improve their practices and delivery of quality care to their patients. Our popular Practice Management Webinars offer the latest expert information and insights to help you navigate through the changes that lay ahead in the new health care landscape. And they offer the flexibility to attend live webinars or access them on demand at a more convenient time.

Purchase webinars individually for $\$ 99$ each, or subscribe to the complete series of 2017 webinars for only $\$ 189$ - that's less than $\$ 19$ per webinar! See the list of webinars and subscribe at $A A N . c o m / v i e w / p m w 17$. 


\section{Neurology}

\section{Unilateral cerebellothalamic tract ablation in essential tremor by MRI-guided focused ultrasound}

Sebastian R. Schreglmann, Ronald Bauer, Stefan Hägele-Link, et al. Neurology 2017;88;1329-1333 Published Online before print March 8, 2017

DOI 10.1212/WNL.0000000000003795

This information is current as of March 8, 2017

\begin{tabular}{|c|c|}
\hline $\begin{array}{l}\text { Updated Information \& } \\
\text { Services }\end{array}$ & $\begin{array}{l}\text { including high resolution figures, can be found at: } \\
\text { http://www.neurology.org/content/88/14/1329.full.html }\end{array}$ \\
\hline Supplementary Material & $\begin{array}{l}\text { Supplementary material can be found at: } \\
\text { http://www.neurology.org/content/supp1/2017/03/08/WNL.0000000000 } \\
\text { 003795.DC1 }\end{array}$ \\
\hline References & $\begin{array}{l}\text { This article cites } 9 \text { articles, } 3 \text { of which you can access for free at: } \\
\text { http://www.neurology.org/content/88/14/1329.full.html\#\#ref-list-1 }\end{array}$ \\
\hline Subspecialty Collections & $\begin{array}{l}\text { This article, along with others on similar topics, appears in the } \\
\text { following collection(s): } \\
\text { Clinical trials Observational study (Cohort, Case control) } \\
\text { http://www.neurology.org//cgi/collection/clinical_trials_observational_ } \\
\text { study_cohort_case_control } \\
\text { Tremor } \\
\text { http://www.neurology.org//cgi/collection/tremor }\end{array}$ \\
\hline Permissions \& Licensing & $\begin{array}{l}\text { Information about reproducing this article in parts (figures,tables) or in } \\
\text { its entirety can be found online at: } \\
\mathrm{http} / / \text { www.neurology.org/misc/about.xhtml\#permissions }\end{array}$ \\
\hline Reprints & $\begin{array}{l}\text { Information about ordering reprints can be found online: } \\
\text { http://www.neurology.org/misc/addir.xhtml\#reprintsus }\end{array}$ \\
\hline
\end{tabular}

Neurology ${ }^{\circledR}$ is the official journal of the American Academy of Neurology. Published continuously since 1951, it is now a weekly with 48 issues per year. Copyright (O 2017 American Academy of Neurology. All rights reserved. Print ISSN: 0028-3878. Online ISSN: 1526-632X.

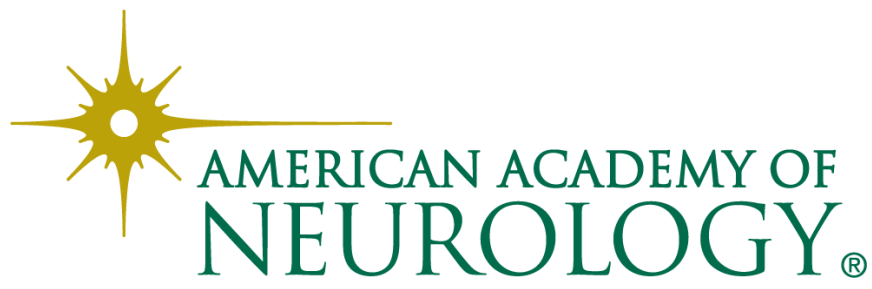

